\title{
Experimental Model of WECS Using Mathematical Approach
}

\author{
Abdellatif ELMANSOURI ${ }^{\# 1}$, Jamal ELMHAMDI ${ }^{\# 2}$ \\ \# Electrical Engineering Laboratory, ENSET, Mohamed V University, Rabat, Morocco \\ ${ }^{1}$ abdellatif.elmansouri@um5s.net.ma \\ 2 mhamdi_jamal@yahoo.fr
}

\begin{abstract}
This paper present a mathematical approach to modelling a wind turbine generator of short term wind power estimated for a wind power plant by support vector machine based on historical data of wind speed and wind power. There are two steps in the process of wind power estimation. In the first step, raw data collected by plant information system. This step prepares valid data to be used for building an estimated model. In the second step, a curve fitting tools is applied to build a model to estimate wind power. The test results of the estimated model are presented and discussed at the end of the paper. The model proposed is shown to achieve a high accuracy with respect to the measured data.
\end{abstract}

Keyword- Curve fitting tools, DFIG, Estimation, Wind turbine.

\section{INTRODUCTION}

Installation of wind energy conversion systems and rate of benefiting from the wind energy has greatly increased in the last two decades, especially in recent years. The latter is due to both ofa significant decrease in costs of wind power production and technological developments in wind turbine production. The contribution of wind energy in electrical power production systems has increased rapidly [1]. Climate warming and the energy crisis over the past few decades have motivated the use and development of alternative, sustainable, and clean energy sources. Wind energy is inexhaustible and considered a renewable resource most used to generate electricity. Wind energy is one of the renewable energy source (RES) characterized by the lowest cost of electricity production and the largest resource available. Therefore, a number of countries are beginning to recognize that wind power provides a significant opportunity for future power generation. The generation of electricity by wind turbines depends on the wind strength at a given time. It is therefore variable but not unpredictable. The wind farms are selected from in-depth studies (usually after the assessment of wind energy potential of the site from wind measurement masts) to determine the characteristics of the wind resource available including its potential power and its orientation at different times of a day and a year. This allows the exploitable yield information that will be made available to the electricity grid managers.

\section{Modeling OF THE WIND TURBINE}

As we found in the literature, several types of modeling power coefficient, often all limits by the input data, so generally valid for a particular turbine: each turbine to a specific behavior.

The evolution of the power coefficient $C_{p}$ depends on aerodynamic characteristics of the wind turbine as well as operating conditions. For a fixed-pitch $\beta$, the ${ }^{C_{p}}$ power coefficient can be expressed as a gear ratio function $\lambda$. On the other hand, a variable pitch angle, the power coefficient can be expressed as a function of $\lambda$ and $\beta$ (fig.4). The total kinetic power available on a wind turbine is given by [2]:

$P_{\max }=\frac{1}{2} \rho S v_{v}^{3}=\frac{1}{2} \rho \pi R^{2} v_{v}^{3}$

The aerodynamic power is given by:

$P_{\max }=\frac{1}{2} C_{p}(\lambda) \rho \cdot \pi \cdot R^{2} \cdot v_{v}^{3}$

$C_{p}=f(\lambda, \beta)=C_{1}\left(\frac{C_{2}}{\lambda_{i}}-C_{3} \beta-C_{4}\right) e^{\left(\frac{C_{5}}{\lambda_{i}}\right)}+C_{6} \lambda$

With:

$$
\begin{aligned}
& C_{\text {turbine }}=\frac{p_{m}}{\Omega_{1}}=\frac{1}{2 \Omega_{1}} C_{p}(\lambda) \rho \pi R^{2} v_{1}^{3} \\
& P_{m g}=C_{p} P_{m}=\frac{1}{2} C_{p}\left(\frac{R \Omega_{2}}{K V_{1}}\right) \rho \pi R^{2} v_{1}^{3}
\end{aligned}
$$


$\frac{1}{\lambda_{i}}=\frac{1}{\lambda+0.08 \beta}-\frac{0.035}{\beta^{3}+1}$

Multiplier model:

$C_{\text {mec }}=\frac{C_{\text {turbine }}}{G}$

A. Model of the shaft:

The fundamental equation of dynamics can be written:

$J \frac{d \Omega_{\text {mec }}}{d t}=C_{\text {turbine }}-f \Omega_{\text {mec }}$

With: $\Omega_{\text {mec }}=G \Omega_{\text {turbine }}$

$J \frac{d \Omega_{m e c}}{d t}=C_{m e c}-C_{e m}-f \Omega_{m e c}$

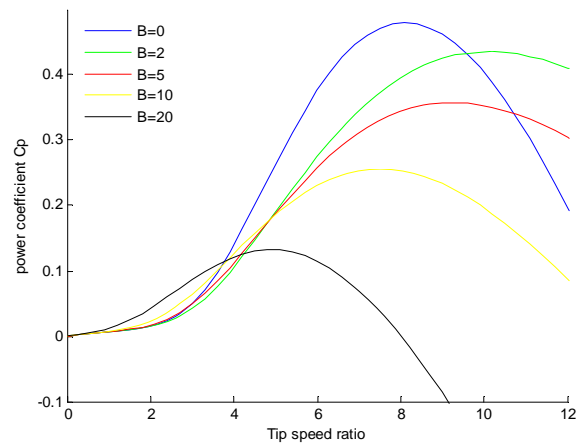

Fig.1: Power coefficient $C_{p}(\lambda, \beta)$

The figure (1) shows the $C_{p}$ curves for multiple values of $\beta$. This curve is characterized by the optimum point; this value is called the Betz limit. To operate with a wind whose speed is greater than a nominal value and to increase the electrical power, the angle of the wind turbine blades is controlled to maintain the power output close to its nominal value. This command allows us to operate with higher wind speeds to $V_{n}$ provided that wind supports the mechanical constraints.

\section{Modeling OF THE DFIG}

The mathematical models of three phases DFIG in the Park frame are written as follows [3]:

$$
\begin{aligned}
& \left\{\begin{array}{l}
V_{d s}=R_{s} I_{d s}+\frac{d \Phi_{d s}}{d t}-\omega_{s} \Phi_{q s} \\
V_{q s}=R_{s} I_{q s}+\frac{d \Phi_{q s}}{d t}+\omega_{s} \Phi_{d s} \\
V_{d r}=R_{r} I_{d r}+\frac{d \Phi_{d r}}{d t}-\omega_{r} \Phi_{q r} \\
V_{q r}=R_{r} I_{q r}+\frac{d \Phi_{q r}}{d t}+\omega_{r} \Phi_{d r}
\end{array}\right. \\
& \left\{\begin{array}{l}
\Phi_{d s}=L_{s} I_{d s}+L_{m} I_{d r} \\
\Phi_{q s}=L_{s} I_{q s}+L_{m} I_{q r} \\
\Phi_{d r}=L_{r} I_{d r}+L_{m} I_{d s} \\
\Phi_{q r}=L_{r} I_{q r}+L_{m} I_{q s}
\end{array}\right.
\end{aligned}
$$

The electromagnetic torques is expressed as: 


$$
C_{e m}=-\frac{3}{2} p \frac{L_{m}}{L_{s}} \phi_{d s} I_{d r}
$$

The active and reactive power is expressed as:

$$
\left\{\begin{array}{l}
P_{s}=V_{q s} I_{q s}+V_{d s} I_{d s} \\
Q_{s}=V_{q s} I_{d s}-V_{d s} I_{q s}
\end{array}\right.
$$

The previous equations used to establish a block diagram of the electrical system:

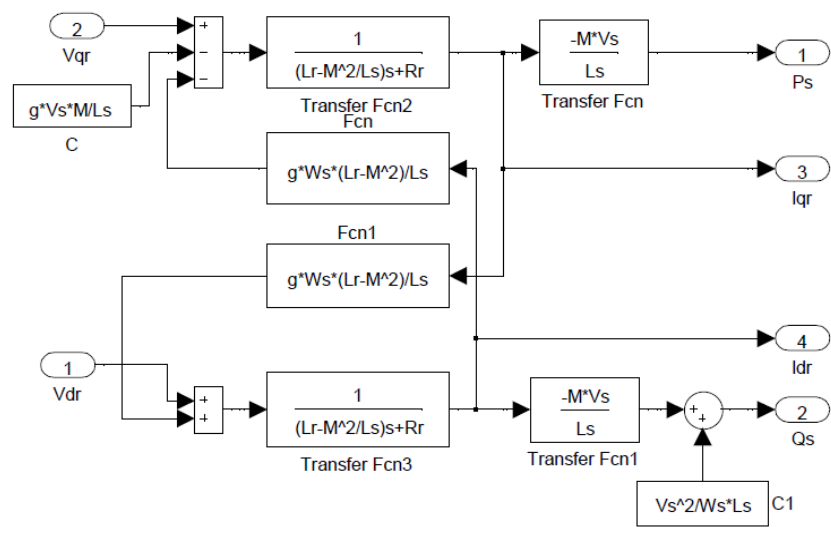

Fig.2: Block diagram of the DFIG.

IV. DATA PREPARATION

In mathematical modeling, a data preparation process is a very important step, since the quality of raw data acquired may contain errors.

B. DATA description and analysis:

The turbine that we will study is a $2.5 \mathrm{Kw}$, it is a three bladed horizontal axis model.

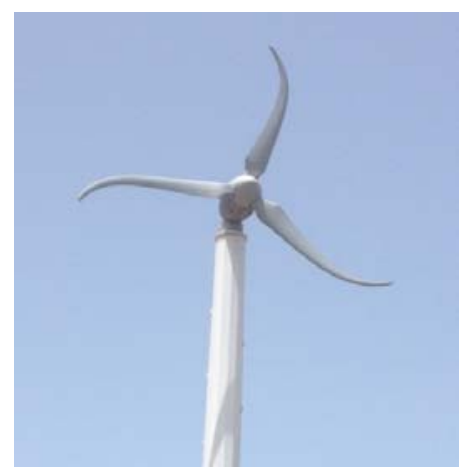

Fig.3: Wind turbine model

Table I: The wind turbine data

\begin{tabular}{|c|c|c|}
\hline Signification & Symbol & Value \\
\hline Blade Radius & $R$ & $3 \mathrm{~m}$ \\
\hline Base wind speed & $V$ & $12 \mathrm{~m} / \mathrm{s}$ \\
\hline Power coefficient & $C_{p}$ & 0.48 \\
\hline $\begin{array}{c}\text { Optimal relative } \\
\text { wind speed }\end{array}$ & $\lambda$ & 8.1 \\
\hline Moment of inertia & $J$ & $0.3125 \mathrm{~kg} / \mathrm{m}^{2}$ \\
\hline
\end{tabular}


Table II: Data description

\begin{tabular}{|c|c|c|c|c|}
\hline $\begin{array}{l}\text { Data } \\
\text { group }\end{array}$ & Start time & End time & $\begin{array}{c}\text { No. of Data } \\
\text { points }\end{array}$ & $\begin{array}{c}\text { Descriptio } \\
n\end{array}$ \\
\hline A & $\begin{array}{l}23 / 03 / 20 \\
1600: 00\end{array}$ & $\begin{array}{c}24 / 032016 \\
23: 59\end{array}$ & 6725 & $\begin{array}{l}\text { Training } \\
\text { data set }\end{array}$ \\
\hline B & $\begin{array}{l}23 / 03 / 20 \\
1600: 00\end{array}$ & $\begin{array}{c}24 / 03 / 2016 \\
23: 59\end{array}$ & 6724 & $\begin{array}{l}\text { Testing } \\
\text { data set }\end{array}$ \\
\hline
\end{tabular}

The data of wind speed $(\mathrm{m} / \mathrm{s})$ and output power $(\mathrm{w})$, are monitored by sensors installed at the tower. All the data acquired is averaged over a one second period for turbine power curve measurement. The following figure presents a plot of data wind speed and output power.

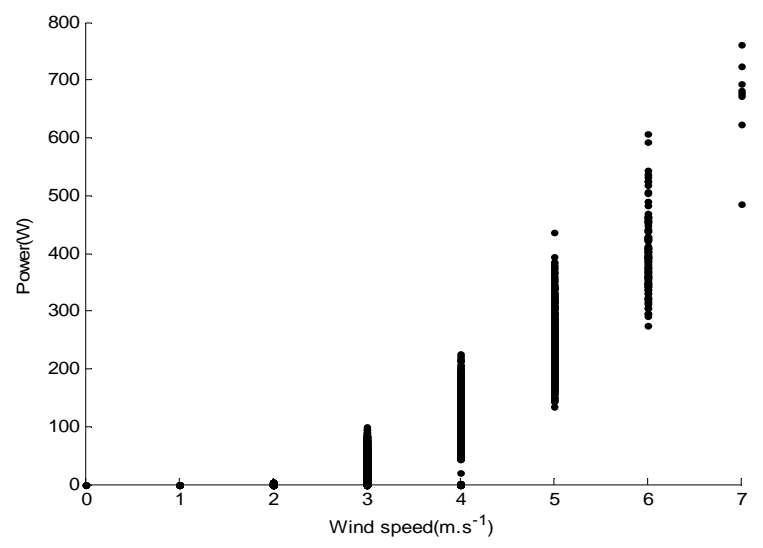

Fig.4: Group A data of power and wind speed.

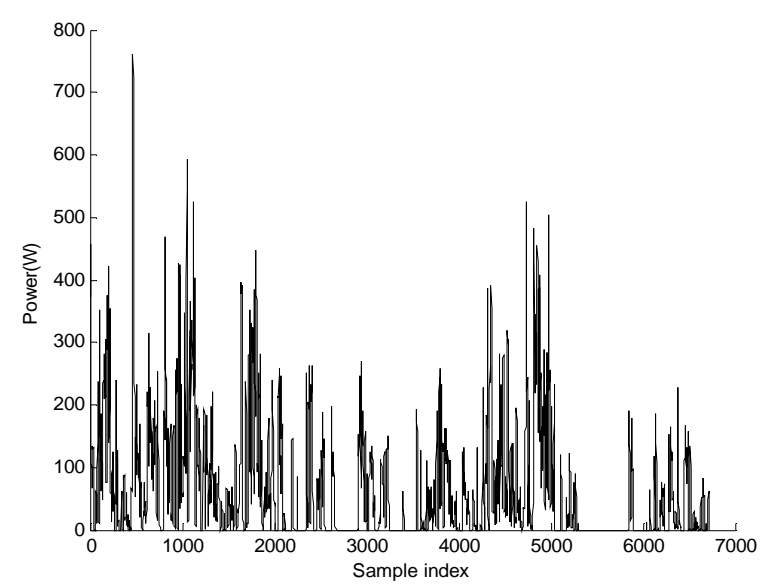

Fig.5: Plot of power data points.

\section{Data for building model}

The estimated power result of the WECS (wind Energy Conversion System) is based on wind speed. This key point is used to determine the available estimated power generated from a wind turbine. The wind speed experienced by wind turbine is acquired by the anemometer. The following figure presents the block diagram of our system [4].

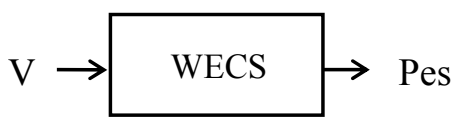

Fig.6: block diagram of our system.

The power estimated is a static function of wind speed, and characterized by the following equation: 


$$
P_{e s}=\sum_{n=0}^{\infty} a_{n} V^{n}
$$

In the modeling process, we use the Group A's data for training the model and the Group B's data for testing/validating the model. In this step we were modeling the WECS output power characteristic. The output power is highly dependent on the wind speed (V). Our objective is to calculate the coefficients $a_{n}$ in order to determine the estimated power ( $a_{n}$ are the coefficients of polynomial Pes) [5].

\section{Simulation RESUltS}

The estimated power will be calculated using curve fitting tool in the MATLAB Simulink. The advantage of this method to estimate the power generated by the Wind Energy Conversion System does not depend on time [6]. Curve fitting refers to fitting curved lines to data. The curved line comes from regression techniques, or interpolation. The data measured from a sensor. The goal of curve fitting is to gain insight into data. The insight will enable us to improve data acquisition techniques for future experiments, accept or refute a theoretical model, extract physical meaning from fitted coefficients, and draw conclusions about the data's parent population[7].

Table III: The degree of the polynomial and the RMSE

\begin{tabular}{|c|c|}
\hline $\boldsymbol{n}$ & $\boldsymbol{R M S E}$ \\
\hline 1 & 8.7733 \\
\hline 2 & 7.8731 \\
\hline 3 & 7.7723 \\
\hline 4 & 7.7711 \\
\hline 5 & 7.7606 \\
\hline
\end{tabular}

From the table above, the results show that the second line has a good performance in the CFT model and can be adopted to build power model for WECS. According to the equation (15) the model of our system is described by a second degree polynomial [8]:

$$
\begin{gathered}
P_{e s}=\mathrm{a}_{1} V^{2}+\mathrm{a}_{2} V+\mathrm{a}_{3} \\
\text { With }\left\{\begin{array}{l}
\mathrm{a}_{1}=18.54 \\
\mathrm{a}_{2}=-49.89 \\
\mathrm{a}_{3}=13.38
\end{array}\right.
\end{gathered}
$$

The power estimated is a static function of wind speed present by the following figure:

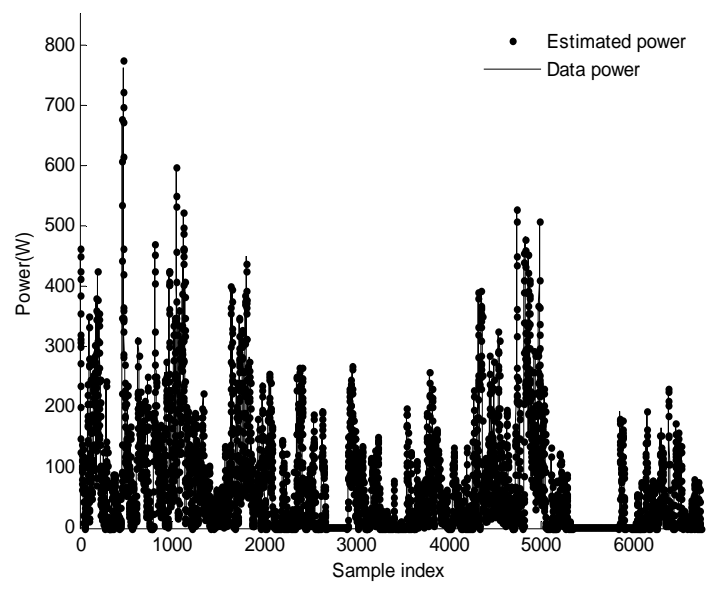

Fig.7: Wind turbine output power variation of estimated and data power with change in wind speed. 


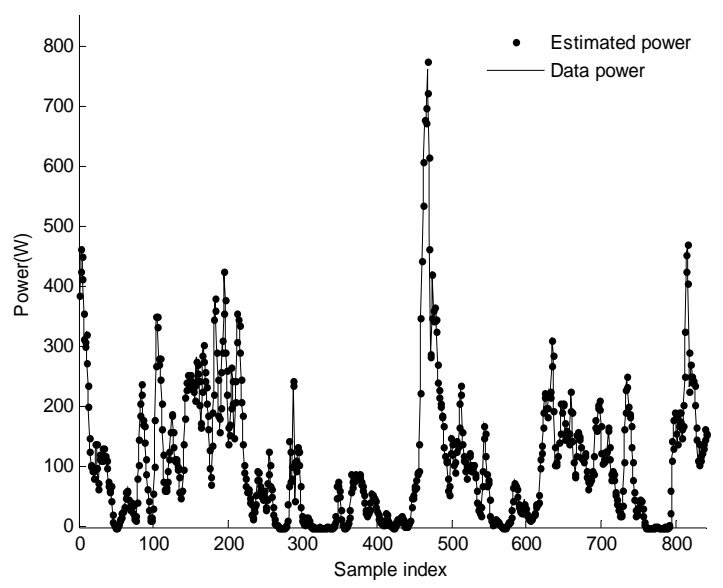

Fig.8: Zoom of wind turbine output power variation of estimated and data power with change in wind speed.

\section{Evaluating the Goodness of Fit}

After fitting data with models, we should evaluate the goodness of fit. A visual examination of the fitted curve is displayed in the Curve Fitting Tool. Figures $(7,8)$ allow us to visualize both integer data, and they can display a wide range of relationships between model and data.

\section{E. Comparison between physical and estimated model:}

In this step we applied different sets of wind speed on both models. The first is estimated based on a database of wind speed and power generated by the wind turbine and the second is modeled by physical equations in order to trace the response of the power generated by each model. Simulation results show clearly that the estimated model gives good results compared to the physical system. During the modeling of latter model many parameters are neglected to simplify calculations, which makes it a bit far from the real system model. The following figure shows the response of physical and estimated model with a change of wind speed.
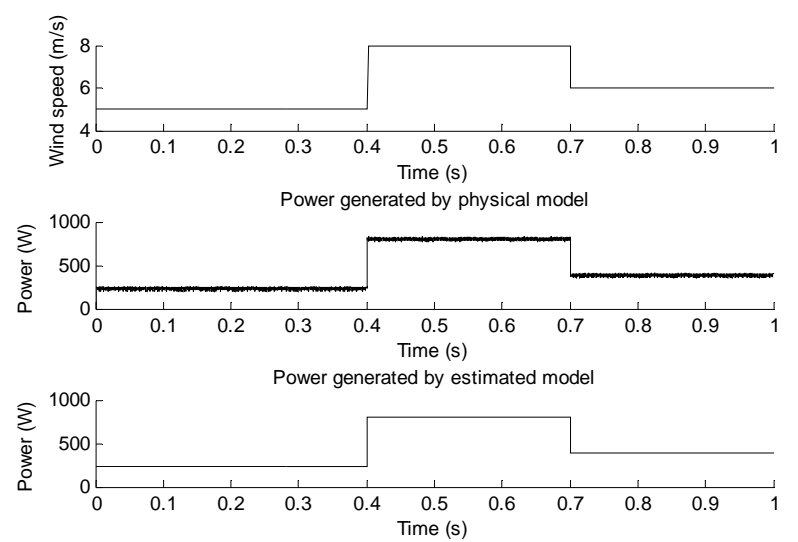

Fig.9: Wind turbine output power variation of physical and estimated model with change in wind speed.

\section{CONCLUSION}

The first part of this work presents the modeling of the turbine and the machine based on physical equations. The second part presents a procedure to determine the available estimated power generated from a wind turbine, using the curve fitting tool in the Matlab Simulink. The estimated model is based on a historical data of WECS. Finally we present a comparative study between the powers generated by the estimated and physical model.

\section{VII.REFERENCES}

[1] C.D'Annunzio; S.Santoso, "Wind power generation reliability analysis and modeling”, Pp 35 - 39 Vol. 1, 2005.

[2] Chao Sheng, Jie Zeng, Wenjia Chu, Yuan Zeng, "Study on Modeling Simulation and Identification of Wind Generator Based on DIgSILENT", in the Asia-Pacific Power and Energy Engineering Conference, pp 1-5, 2012.

[3] A.Elmansouri,J.Elmhamdi,A.Boualouch,A.Aamoud,"MPPT control of DFIG in WECS using back-stepping controller", in the 3rd International Renewable and Sustainable Energy Conference (IRSEC), pp 1 - 7, 2015.

[4] P.C. Răzuşi, M. Eremia, "Prediction of Wind Power by Artificial Intelligence Techniques", pp 1 - 6, 2011.

[5] A. Monroy and L. Alvarez-Icaza, "Real-time identification of wind turbine rotor power coefficient", in the 45th IEEE Conference on Decision \& Control, pp 3690 - 3695, December 13-15, 2006. 
[6] Shoudao Huang, Ziqiang Chen, Keyuan Huang, Jian Gao, "Maximum Torque Per Ampere and Flux-weakening Control for PMSM Based on Curve Fitting", in the IEEE Vehicle Power and Propulsion Conference, pp 1-5, 2010.

[7] Xiaochen Wang, Peng Guo, Xiaobin Huang, "A Review of Wind Power Forecasting Models" in the ICSGCE,pp 770 - 778, September 2011.

[8] RoyBillinton; YiGao, "Multistate Wind Energy Conversion System Models for AdequacyAssessment of Generating Systems Incorpor ating Wind Energy", in the IEEE TRANSACTIONS ON ENERGY CONVERSION, pp 163 - 170, VOL. 23, NO. 1, MARCH 2008

VIII. APPENDIX

Table IV: the Wind turbine data

\begin{tabular}{|c|c|c|}
\hline Signification & Symbol & value \\
\hline Blade Radius & $R$ & $3 \mathrm{~m}$ \\
\hline Base wind speed & $V$ & $12 \mathrm{~m} / \mathrm{s}$ \\
\hline $\begin{array}{c}\text { Power coefficient } \\
\text { Optimal relative wind } \\
\text { speed }\end{array}$ & $C_{p}$ & 0.48 \\
\hline Moment of inertia & $J$ & $0.3125 \mathrm{~kg} / \mathrm{m}^{2}$ \\
\hline
\end{tabular}

Table V: the DFIG parameters

\begin{tabular}{|c|c|c|}
\hline Signification & Symbol & Value \\
\hline Rated power & $P$ & $2.5 \mathrm{~kW}$ \\
\hline Rated stator voltage & $V_{s}$ & $220 \mathrm{~V}$ \\
\hline $\begin{array}{c}\text { Nominal frequency } \\
\text { Number of pole } \\
\text { pairs }\end{array}$ & $\omega_{s}$ & $2 \pi 50$ \\
\hline $\begin{array}{c}\text { Rotor resistance } \\
\text { Stator resistance }\end{array}$ & $R_{r}$ & 2 \\
\hline $\begin{array}{c}\text { Stator inductance } \\
\text { Rotor inductance }\end{array}$ & $L_{s}$ & $0.62 \Omega$ \\
\hline Mutual inductance & $M$ & $0.455 \Omega$ \\
\hline Sliding & $g$ & $0.085 \mathrm{H}$ \\
\hline
\end{tabular}

The power coefficient constants

$$
\left\{\begin{array}{l}
c_{1}=0.5176 \\
c_{2}=116 \\
c_{3}=0.4 \\
c_{4}=5 \\
c_{5}=-21 \\
c_{6}=0.0068
\end{array}\right.
$$


Table VI: the list of symbols

\begin{tabular}{|c|c|}
\hline Symbol & Signification \\
\hline$\rho$ & Air density \\
\hline$R$ & Blade radius \\
\hline$V_{v}$ & Wind speed (m/s) \\
\hline$P_{\max }$ & Wind maximum power \\
\hline$C_{p}$ & Power coefficient \\
\hline$\lambda$ & Relative wind speed \\
\hline$\Omega_{1}$ & Wind turbine speed(Shaft speed) \\
\hline$\Omega_{\text {mec }}$ & Wind turbine torque (Nm) \\
\hline$C_{\text {mec }}$ & Electromagnetic torque(Nm) \\
\hline$C_{e m}$ & Mechanical speed multiplier \\
\hline$G$ & Direct and quadrature rotor voltages \\
\hline$V_{d r}, V_{q r}$ & Moment of inertia(Kg.m $\left.{ }^{2}\right)$ \\
\hline$J$ & Damping coefficient \\
\hline$f$ & Wind turbine torque (Nm) \\
\hline$C_{\text {turbine }}$ & rpm) \\
\hline
\end{tabular}

AUTHOR PROFILE

Abdellatif ELMANSOURI PhD student, was born in 1987 in Morocco, he received her Master's degree in Electrical Engineering from Higher Normal School of Technical Education (Ecole Normale Supérieure de l'Enseignement Technique - ENSET), Rabat Mohammed V University, Morocco, in 2012. he is actually a PhD student since 2013 in Sciences and Technology of the Engineer in the National School of Computer Science and Systems Analysis (Ecole Nationale Supérieure d'Informatique et d'Analyse des Systèmes - ENSIAS), Research Laboratory in Electrical Engineering LRGE, located in the Higher Normal School of Technical Education ENSET, Mohammed V University, Rabat, Morocco. He is author or co-author of several papers in international conferences and journals. His research interests include the renewable energy.

Jamal ELMHAMDI received the master degree EEA in 1984 and the $\mathrm{PhD}$ in signal processing and Telecommunications by the University of Rennes (France) in 1988 he was professor in the Mohammed V University in Morocco. He manages the Team of Research in Computer Science and Telecommunications. He is currently professor in Higher Normal School of Technical Education (Ecole Normale Supérieure de l'Enseignement Technique - ENSET), Rabat Mohammed V University, Morocco. He is author or co-author of several papers in international conferences and journals. His domains of interest include signal processing and telecommunications. He is also a member of the reading committee of several international conferences and journals. He has supervised and co-supervised several doctoral theses. His research interests include the problems of implementing signal processing algorithms and image on DSP and FPGA in the real-time embedded systems. 